\title{
Occlusion of the HIV poly(A) site
}

\author{
Caroline Weichs an der Glon, Joan Monks, and Nick J. Proudfoot \\ Sir William Dunn School of Pathology, University of Oxford, Oxford OX1 3RE UK
}

To investigate the selective use of poly(A) sites in the $3^{\prime}$ long terminal repeat (LTR) but not the $5^{\prime}$ LTR of retroviruses, we have studied the poly(A) site of the human immunodeficiency virus (HIV-1). Using hybrid HIV/a-globin gene constructs, we demonstrate that the HIV poly(A) site is inactive or occluded when adjacent to an active promoter, either the homologous HIV promoter or the $\alpha$-globin gene promoter. Furthermore, this occlusion of the HIV poly(A) site occurs over a considerable distance of up to at least $500 \mathrm{bp}$. In contrast, two nonretroviral poly(A) sites [ $\alpha$-globin and a synthetic poly(A) site] are active when close to a promoter. We also show that a short fragment of $\sim 60$ nucleotides containing the HIV poly(A) site is fully active when placed at the $3^{\prime}$ end of the human $\alpha$-globin gene or within the rabbit $\beta$-globin gene. This result rules out the requirement of more distant upstream elements for the activity of the HIV poly(A) site, as has been suggested for other viral poly(A) sites. Finally, we show that the GT-rich downstream region of the HIV poly(A) site confers poly(A) site occlusion properties on a synthetic poly(A) site. This result focuses attention on this more variable part of a poly(A) site in retrovirvses as a possible general signal for poly $(\mathbf{A})$ site occlusion.

[Key Words: Poly(A) sites; HIV-1; LTRs; retroviral transcription]

Received August 9, 1990; revised version accepted November 26, 1990.

The duplication of transcriptional control sequences in the long terminal repeats (LTRS) of retroviruses presents unusual regulatory features. The promoter in the $5^{\prime}$ LTR initiates transcription that reads through the adjacent poly $(\mathrm{A})$ site into the viral genes beyond. Transcription then proceeds into the $3^{\prime}$ LTR forming a polyadenylated $3^{\prime}$ terminus at the identical poly(A) site in the $3^{\prime}$ LTR. As shown in Figure $1 \mathrm{~A}$, this pattern of transcription is achieved by somehow inactivating both the poly(A) site in the $5^{\prime}$ LTR and the promoter in the $3^{\prime}$ LTR even though identical copies of these two transcription signals are highly active in the opposite LTR /Varmus 1988).

A molecular explanation for the inactivity of the $3^{\prime}$ LTR promoter may be that of transcriptional interference. Cullen et al. (1984) demonstrated that in the avian leukosis retrovirus (ALV), transcription from the 5' LTR directly inactivates the $3^{\prime}$ LTR promoter. This inactivation could be alleviated by either deleting the $5^{\prime}$ LTR promoter or by placing SV40 termination of transcription signals between the two LTRs. Presumably, transcription reading into the $3^{\prime}$ LTR blocks the formation of a transcription initiation complex, as has been shown in RNA polymerase I genes (Bateman and Paule 1988; Henderson et al. 1989).

The molecular basis of retroviral poly(A) site occlusion is uncharacterized. In some cases, such as the Rous sarcoma virus (Ju and Cullen 1985), the transcription initiation site lies between the two parts of the poly(A) signal: the $\mathrm{A}_{2} \mathrm{UA}_{3}$ and GU-rich sequence elements (Humphrey and Proudfoot 1988). Consequently, the 5' LTR poly(A) site is inactive because the complete RNA pro- cessing signal is absent from the transcript. However, more commonly, the poly(A) signals of retroviruses are $50-100$ bp $3^{\prime}$ to the transcription start site so that the whole RNA processing signal should be within the RNA transcript (Varmus 1988).

Such is the situation in the human immunodeficiency virus HIV-1, where the transcription start site is 72 bp 5' to the poly(A) signal (Fig. 1B) (Ratner et al. 1987). Both the high levels of transcription achieved by HIV, as well as the intense interest in characterizing the molecular mechanisms that regulate it, prompted us to investigate HIV poly(A) site occlusion in more detail. To do this, we have set up a model system by making hybrid HIV LTR/ human $\alpha 2$-globin gene constructs with the LTR in place of the $\alpha$-globin promoter, as well as positioned at the $3^{\prime}$ end of the $\alpha$-globin gene. Using these constructs, we demonstrate both poly(A) site occlusion in the $5^{\prime}$ LTR and transcriptional interference in the $3^{\prime}$ LTR. We have gone on to characterize the poly $|A|$ site occlusion more thoroughly. First, the HIV poly(A) site functions efficiently when separated from its adjacent promoter and placed either at the $3^{\prime}$ end of the $\alpha$-globin gene or within the rabbit $\beta$-globin gene. However, the HIV poly(A) site does not function significantly when positioned immediately $3^{\prime}$ to an active promoter, either its homologous HIV promoter or the $\alpha$-globin promoter. Second, in contrast with the HIV poly(A) site, other $\operatorname{poly}(\mathrm{A})$ sites are active when adjacent to either the HIV or $\alpha$-globin promoters. Our results suggest that the HIV poly(A) site and, in particular, its downstream GT-rich region possess specific sequence features that render it sensitive to transcription from an immediately adjacent promoter. 
A

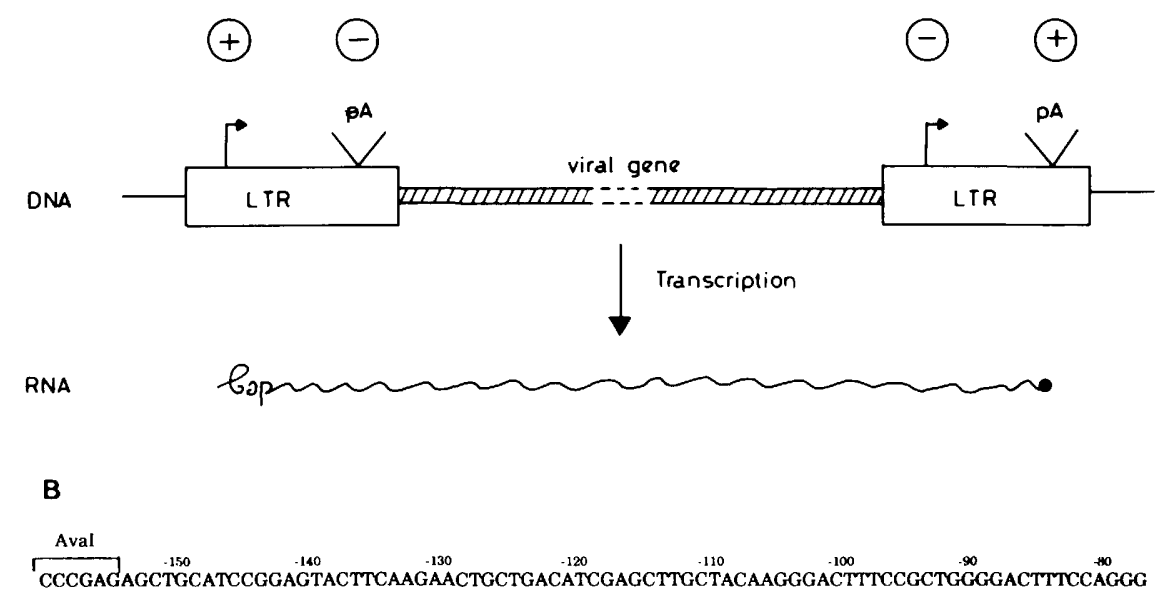

AGGCGTGGCCTGGGCGGGACTGGGGAGTGGCGAGCCCTCAGATCCTGCATATAAGCAGCTGCTTTTTGCCTGTACT

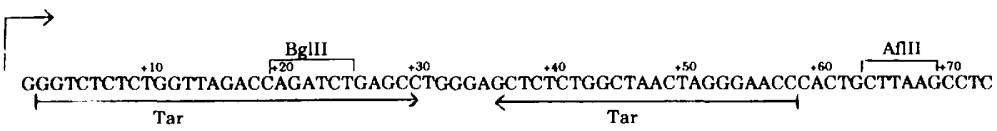

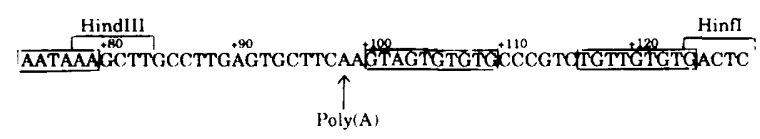

\section{Results}

Hybrid HIV LTR/ $\alpha$-globin gene constructs reproduce viral transcriptional regulation

To set up a convenient experimental system to investigate poly(A) site occlusion in the HIV LTR sequence, we constructed chimeric DNAs in which portions of the HIV LTR were fused to equivalent parts of the human $\alpha 2$-globin gene. Two such constructs were initially investigated, one containing the HIV LTR promoter and leader sequence in place of the $\alpha$-globin promoter region $(\mathrm{L} \alpha)$ and the other containing a second copy of the HIV LTR sequence in place of the $3^{\prime}$ end of the $\alpha$-globin gene, including its poly $(\mathrm{A})$ signal $(\mathrm{L} \alpha \mathrm{L})$. The HIV LTR sequence present in $\mathrm{L} \alpha$ and $\mathrm{L} \alpha \mathrm{L}$ starts from an $A v a \mathrm{I}$ site $(-160)$ in the $5^{\prime}$-flanking region and includes all of the HIV enhancer and promoter elements (Jones 1989). The HinfI site $(+128)$ at the $3^{\prime}$ end of the LTR fragment immediately follows the GT-rich sequences that are part of the HIV poly(A) signal, as directly demonstrated by Bohnlein et al. (1989). The HIV LTR sequence is shown in Figure $1 \mathrm{~B}$ while $\mathrm{L} \alpha$ and $\mathrm{L} \alpha \mathrm{L}$ are depicted in Figures $2 \mathrm{~A}$ and $3 \mathrm{~A}$. $L \alpha$ and $L \alpha \mathrm{L}$ are within the transient expression vector pSVed (Proudfoot et al. 1984), which contains both the SV40 origin of replication and enhancer sequences. We have recently discovered that the HIV promoter is activated by DNA replication (N.J. Proudfoot and J. Monks, in prep.). We therefore transfected HeLa cells with either $L \alpha$ or $L \alpha L$ pSVed, together with a second plasmid R $\beta S V p B R 328$. This plasmid expresses both $\mathrm{T}$ antigen, thereby allowing replication of the pSVed
Figure 1. (A) Schematic illustration of transcription in a retroviral system, demonstrating the occlusion of the polyadenylation site in the 5' LTR and inactivation of the promoter in the $3^{\prime}$ LTR. Active or inactive promoters and poly $(\mathrm{A})$ sites are denoted by + and - , respectively. (B) Sequence of the long terminal repeat (LTR) fragment (AvaI-HinfI) obtained from HIV1 (Ratner et al. 1987). The LTR fragment contains the HIV-1 LTR promoter/ enhancer region with the TATA box sequence underlined and transcription start site indicated by an arrow. The poly(A) site signals, AATAAA, and two GT-rich regions are boxed, with the site of poly(A) addition indicated. The inverted repeat region that confers Tat responsiveness on the HIV promoter /Cullen and Greene 1989 | is indicated by Tar. Finally, various restriction sites employed in these studies are bracketed. plasmids, and rabbit $\beta$-globin mRNA, which provides a useful control for efficiency of transfection (Grosveld et al. 1982).

Figure 2B shows RNA mapping experiments performed on cytoplasmic RNA purified from HeLa cells transfected with either $\mathrm{L} \alpha$ or $\mathrm{L} \alpha \mathrm{L}$ pSVed. Panel I shows the RNase-protected bands obtained using a riboprobe as indicated in Figure 2A. L $\alpha$ gave one band that corresponds to a transcript that initiates at the HIV cap site and then reads through the HIV poly(A) site into the $\alpha$-globin gene beyond. The HIV poly(A) site would therefore appear to be inactive in $L \alpha$ (see below).

$\mathrm{L} \alpha \mathrm{L}$, as well as giving a $5^{\prime} \mathrm{LTR}$ readthrough band, gave a second larger product of $\& 250$ nucleotides, which corresponds in size to transcripts reading into the $3^{\prime}$ LTR sequence and then ending at the $3^{\prime}$ LTR poly(A) site. No transcripts were detected that initiate at the $3^{\prime}$ LTR promoter. This $3^{\prime}$ LTR readthrough band would be $10 \mathrm{nu}-$ cleotides larger than the $5^{\prime}$ LTR readthrough band because of polylinker sequences present both in the riboprobe and $3^{\prime}$ LTR sequence but absent from the 5' LTR sequence. To confirm the transcription pattern observed for the 3' LTR in $L \alpha \mathrm{L}$, a second RNA mapping experiment was carried out using an end-labeled DNA probe specific for the $3^{\prime}$ LTR (labeled at an XbaI site in the polylinker sequence $5^{\prime}$ to the $3^{\prime}$ LTR; see Fig. $2 A$ ). By S1 analysis as shown in Figure 2B, panel II, $L \alpha L$ but not $L \alpha$ gave a specific band of 260 nucleotides that corresponds to transcripts reading into the $3^{\prime}$ LTR sequence and ending at the $3^{\prime}$ LTR poly(A) site.

The results presented in Figure 2 indicate that the HIV 
Figure 2. (A) Schematic representation of $\mathrm{L} \alpha \mathrm{L}$, a hybrid construct in which the $\alpha 2$-globin gene is flanked by HIV-1 LTRs. $\alpha$-Globin exons (hatched boxes); introns (open boxes); HIV sequence (dashed boxes); flanking sequences (thin boxes); promoter (arrow); poly $(\mathrm{A})$ site $(\mathrm{pA})$; and polylinker regions (solid box) are shown. Both probes used to detect transcripts from these plasmid constructions are shown. The LTR riboprobe was an $\mathrm{XbaI}$ run off transcript (labeled with $\left[{ }^{32} \mathrm{P}\right] \mathrm{UTP}$ ) of plasmid pSP65HIV HA (Materials and methods). The unique BamHI site in the polylinker region of pSP65HIV HA was used to end-label the S1 DNA probe. $(B)$ RNase protection analysis and S1 nuclease analysis of RNA from HeLa cells transfected with $\mathrm{L} \alpha$ and $L \alpha \mathrm{L}$. (I) Control hybridization with tRNA (Co). In $L \alpha$ and $L \alpha L$ the $5^{\prime}$ LTR poly(A) site occlusion and, thus, readthrough $(\mathrm{rt})$ into the $\alpha 2$-globin gene is represented by a band of 125 nucleotides, corresponding to the size of a transcript starting at the $5^{\prime}$ LTR cap site. The absence of a band of 135 nucleotides indicates no 3 ' LTR promoter activity. This band would be 10 nucleotides larger than the $5^{\prime}$ LTR band due to polylinker sequence on its $3^{\prime}$ side present in both $\mathrm{L} \alpha \mathrm{L}$ and the riboprobe. The utilization of the 3' LTR poly(A) site by transcripts initiating from the 5' LTR is demonstrated by a band of 250 nucleotides in the analysis of the construct $L \alpha \mathrm{L}$. (II) In the S1 nuclease analysis using the $\mathrm{L} \alpha \mathrm{L}$ $3^{\prime}$ S1 probe, a band of 260 nucleotides is detected in $\mathrm{L} \alpha \mathrm{L}$, confirming the usage of the $3^{\prime}$ LTR poly(A) site by transcripts initiating on the $5^{\prime}$ LTR promoter. There are no bands detected in the construct $L \alpha$ because the probe was labeled at a site in the polylinker sequence not present in $\mathrm{L} \alpha$.

LTR/ $\alpha$-globin constructs reproduce both poly $(\mathrm{A})$ site occlusion in the $5^{\prime}$ LTR and transcriptional interference in the $3^{\prime}$ LTR. In effect, we have a convenient system in which to investigate these two retroviral regulatory mechanisms. In the following sections we describe experiments that further define the molecular basis of poly(A) site occlusion in HIV.

\section{The HIV poly $(A)$ site is an efficient $3^{\prime}$ processing} signal but inactive when part of the 5' LTR sequence

The observed inactivity of the HIV poly(A) site when part of the 5' LTR $(\mathrm{L} \alpha)$ could be accounted for by the fact that it requires specific sequences $5^{\prime}$ to the cap site. These sequences would be present in the active $3^{\prime}$ LTR poly(A) site but not the $5^{\prime}$ LTR poly(A) site. Indeed, such a sequence requirement has been demonstrated recently for the poly(A) site of the pararetrovirus hepatitis B (Russnak and Ganem 1990) as discussed below. Alternatively, the HIV poly(A) site could be an intrinsically weak RNA-processing signal. However, as shown in Figure $1 \mathrm{~B}$, the HIV poly(A) site has both an AATAAA sequence and an extensive GT-rich region 20 bp downstream, all of which are the hallmarks of an efficient poly(A) site (Gil and Proudfoot 1987).

To test the efficiency of the HIV poly(A) site in isolation, we purified an LTR BglII-HinfI fragment including the poly $(\mathrm{A})$ signal and inserted it $3^{\prime}$ to the human $\alpha 2$-globin gene, as indicated in Figure 3A. The normal $\alpha 2$-globin gene was used $(\alpha \mathrm{WL})$, as well as a mutant gene

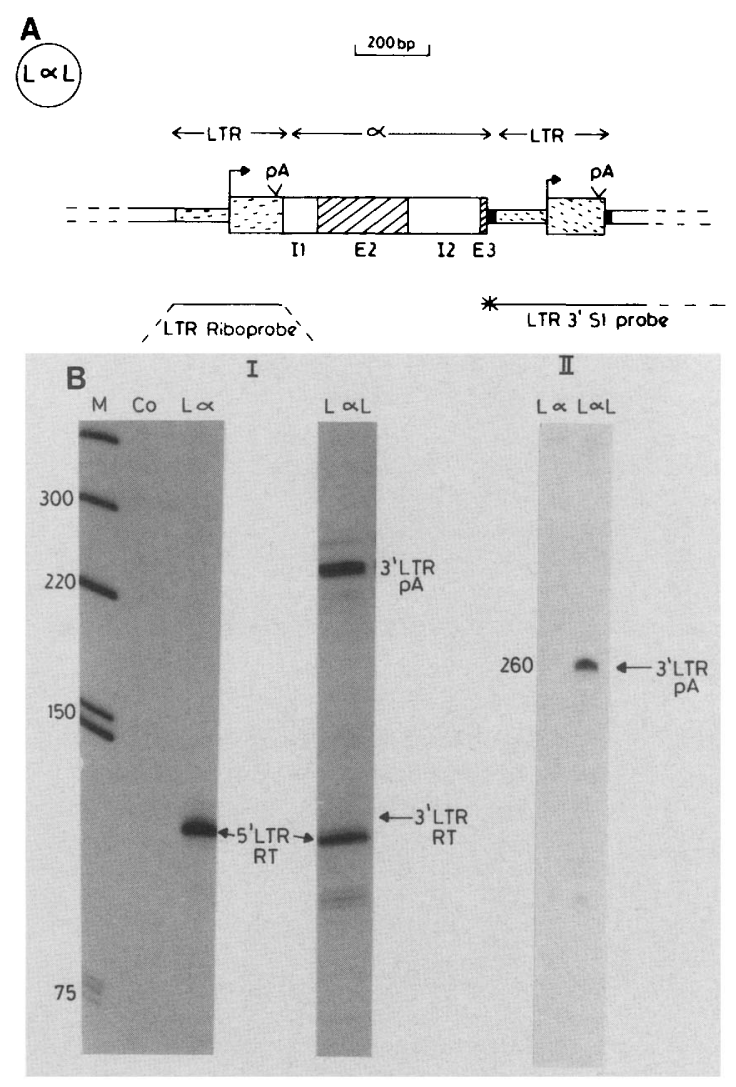

with an inactive poly(A) signal, isolated from a rare form of $\alpha$-thalassemia ( $\alpha \mathrm{ML}$ ) (Higgs et al. 1983). Figure 3B shows the RNA analysis of $\alpha \mathrm{WL}$ and $\alpha M L$ pSVed compared with $\alpha$-pSVed, when transfected into HeLa cells. Using a 3' S1 probe from $\alpha \mathrm{WL}$ (Fig. 3A), $\alpha$-pSVed gave an Sl product of 230 nucleotides as expected for the $3^{\prime}$ end of $\alpha$-globin mRNA. In contrast, both $\alpha M L$ and $\alpha W L$ gave a larger band of 360 nucleotides corresponding to utilization of the HIV poly(A) site. The fact that only $10 \%$ of mRNA utilized the $\alpha$-globin poly(A) site, as compared with $90 \%$ at the HIV poly $(\mathrm{A})$ site in $\alpha \mathrm{WL}$ demonstrates that the HIV poly $(\mathrm{A})$ site is a much stronger RNA-processing signal. These conclusions are based on the observation that if two identical poly(A) sites are placed in tandem, the $5^{\prime}$ site is predominantly utilized (Gil and Proudfoot 1987), while if a stronger poly(A) site is positioned $3^{\prime}$ to a weaker site, the stronger $3^{\prime}$ poly $(\mathrm{A})$ site predominates (Levitt et al. 1989). As predicted, $\alpha M L$ gave no $\alpha$ pA band but only the LpA band, consistent with the inactivity of the mutant $\alpha$-globin poly(A) site.

To characterize the HIV poly(A) site further, we purified an AflIIHinfl fragment from the HIV LTR (see Fig. 1B) that contains only 7 nucleotides 5 ' to the AATAAA sequence with its $3^{\prime}$ end directly following the GT-rich region. This fragment was inserted into the PVuII site in the $3^{\prime}$-flanking region of the $\alpha 2$-globin gene as in $\alpha W L$ to give the subclone $\alpha \mathrm{WL}^{*}$, as well as in a quite different location in the third exon of the rabbit $\beta$-globin gene, 80 nucleotides 5 ' to the $\beta$-globin poly $(\mathrm{A})$ site $(\beta \mathrm{L})$. As shown in Figure $3 \mathrm{C}$, the shorter HIV poly(A) site fragment 
A

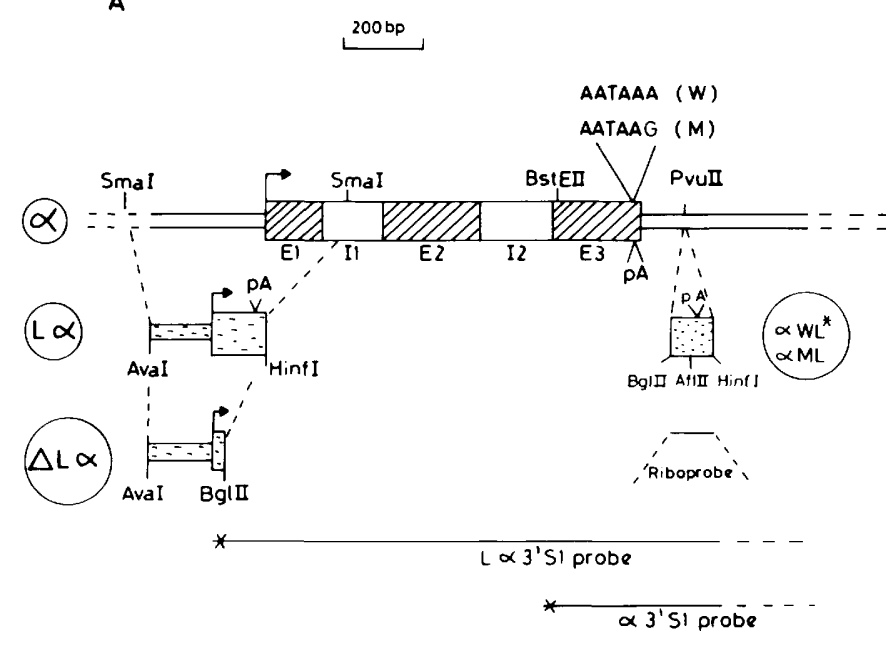

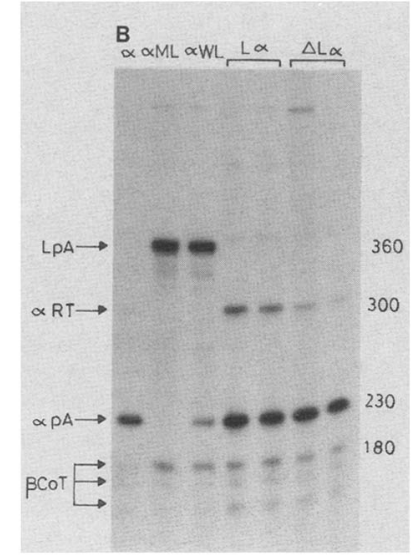

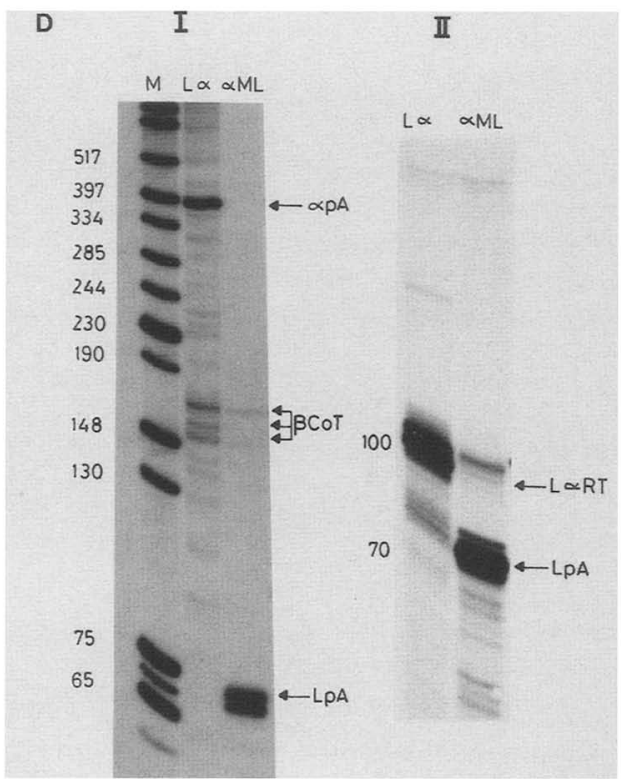

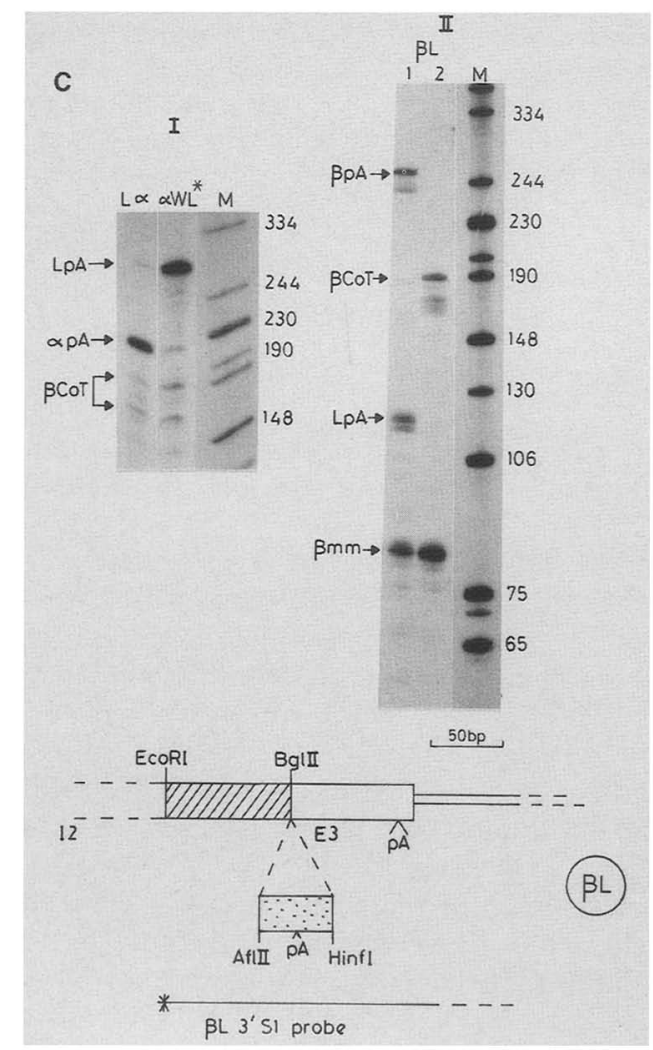

Figure 3. (See following page for legend.)

works efficiently in competition with the $\alpha$-globin poly(A) site. Thus, while $\mathrm{L} \alpha$ gives a strong $\alpha \mathrm{pA}$ site $\mathrm{S1}$ band, $\alpha W^{*}$ largely reads through the $\alpha$-globin poly $(\mathrm{A})$ site to yield an HIV poly(A) site band at $\sim 90 \%$ level. In the clone $\beta \mathrm{L}$ it is evident that almost $50 \%$ of transcripts utilize the HIV poly(A) site with the remaining $50 \%$ reading through to the strong rabbit $\beta$-globin poly $(\mathrm{A})$ site. Lane $\beta \mathrm{L} 1$ shows $\mathrm{S} 1$ analysis using a homologous EcoRI end-labeled probe. The $\beta M M$ band detects mRNA from the cotransfected rabbit $\beta$-globin plasmid, which diverges from $\beta \mathrm{L}$ at the BglII site shown in the diagram
(Fig. 3C). As a control experiment, an EcoRI probe was used from the cotransfected rabbit $\beta$-globin plasmid, which gives two S1 bands (lane $\beta$ L2): one corresponding to the $\beta$-globin poly(A) site and the other to transcripts from $\beta \mathrm{L}$, which again diverge in sequence at the BglII site. On the basis of these results we conclude that the HIV poly(A) site is more efficient than the human $\alpha$-globin poly(A) but less efficient than the rabbit $\beta$-globin poly(A) sites. However, the fact that the minimal HIV poly(A) site functions in two quite different locations indicates that it does not possess an intrinsic 
Figure 3. $\{A \mid$ Schematic representation of further $\alpha 2$-globin/HIV hybrid constructs: $\mathrm{L} \alpha, \Delta \mathrm{L} \alpha, \alpha \mathrm{WL}, \alpha \mathrm{ML}$, and $\alpha \mathrm{WL}$ * $\alpha$ corresponds to the previously described construct $\alpha 2$ W3'PSpSVed (Whitelaw and Proudfoot 1986). Exons (hatched boxes); introns (open boxes); HIV fragments (dashed boxes); flanking sequences (thin boxes); promoters (arrows); poly(A) sites (pA); and important restriction sites are shown. All probes used to detect transcripts from these hybrid constructs are shown. The riboprobe construct pSP65HIV HB (see Materials and methods) was linearized with $X b a I$ and a $\left[{ }^{32} \mathrm{P}\right] \mathrm{UTP}$ run off transcript was synthesized. This probe was used to detect HIV transcripts from $L \alpha$ and $\alpha M L$. The BgIII site in L $\alpha$ was used to end-label the $L \alpha 3^{\prime}$ S1 DNA probe, used for further analysis of $L \alpha$ and $\alpha M L$. The BstEII site in the third exon of the $\alpha 2$-globin gene from $\alpha$ WL was used to end-label the $\alpha 3^{\prime}$ S1 DNA probe, which was hybridized to RNA from $\alpha, \alpha \mathrm{ML}, \alpha \mathrm{WL}, \mathrm{L} \alpha$, and $\Delta \mathrm{L} \alpha .|B| \mathrm{S}$ l nuclease analysis of RNA from HeLa cells transfected with $\alpha, \alpha \mathrm{ML}, \alpha \mathrm{WL}$, $\mathrm{L} \alpha$, and $\Delta \mathrm{L} \alpha$. The analysis of $\mathrm{L} \alpha$ and $\Delta \mathrm{L} \alpha$ was performed in duplicate, using RNA from two separate transfections. All cells were cotransfected with R $\beta$ SVpBR328 (Grosveld et al. 1982), which synthesizes rabbit $\beta$-globin mRNA providing a transfection control. The utilization of the $\alpha 2$-globin poly(A) site is shown by a band of 230 nucleotides; the HIV LTR poly(A) site utilization (located 3' to $\alpha$ in $\alpha \mathrm{ML}$ and $\alpha \mathrm{WL}$ ) is detected by a band of 360 nucleotides. $\alpha, \mathrm{L} \alpha$, and $\Delta \mathrm{L} \alpha$ also give a faint band of 300 nucleotides due to utilization of cryptic poly(A) sites in the $\alpha 3^{\prime}$-flanking region (Whitelaw and Proudfoot 1986). This band derives from sequence divergence between the globin 3 '-flanking region transcripts and the $\alpha$ WL S1 probe at the PvuII site. Finally, the band at 180 nucleotides plus the two satellite bands below (S1 overdigestion products) derive from rabbit $\beta$-globin mRNA produced by the cotransfected R $\beta$ SVpBR328 plasmid using an EcoRI 3'S1 probe mixed with the $\alpha$ WL 3' S1 probe. The relatively constant levels of $\beta$ signal indicate that the different transfections and $\mathrm{S} 1$ analysis were equally efficient. $(C) \mathrm{S} 1$ analysis of $\mathrm{L} \alpha$ and $\alpha \mathrm{WL}^{*}(I)$ and $\beta \mathrm{L}(I I)$. The probes used in panel $I$ are the human $\alpha$ and rabbit $\beta 3^{\prime}$ Sl probes as in Fig. 3B. In $\alpha \mathrm{WL}^{*}$ the $\alpha$-globin poly(A) site is largely outcompeted by the HIV poly(A) site. Panel $I I$ and the diagram below show that the HIV poly(A) site in the third exon of the rabbit $\beta$-globin gene works at nearly $50 \%$ level to the downstream normal $\beta$-globin poly(A) site. Lane 1 uses an EcoRI 3' S1 probe for $\beta \mathrm{L}$; lane 2 uses an EcoRI 3' S1 probe for the normal rabbit $\beta$-globin gene $\{\mathrm{R} \beta S$ SpBR328) cotransfected with $\beta \mathrm{L}$. $\beta \mathrm{mm}$ denotes transcripts that diverge or mismatch with the probe at the $B g$ III site. (D)(I) S1 nuclease analysis of RNA from HeLa cells transfected with L $\alpha$ and $\alpha M L$, cotransfected with R $\beta S V p B R 328$. The $\beta$ control transcripts are represented by bands between 150 nucleotides and 180 nucleoitdes. In $\mathrm{L} \alpha$, with a homologous probe, we detect a band at 390 nucleotides, accounting for the utilization of the $\alpha 2$-globin poly(A) site. No band representing the utilization of the HIV LTR poly(A) site is detectable in $\mathrm{L} \alpha$, whereas in $\alpha \mathrm{ML}$, a band of 74 nucleotides is detected providing a positive control for the utilization of the LTR poly(A) site. (II) RNase protection analysis of the same L $\alpha$ and $\alpha$ ML RNAs. The HIV LTR poly(A) site, 30 bp distant from the end of the LTR (HinfI site), accounts for the difference in transcript length between L $\alpha$ and $\alpha M L$. The shorter transcript (74 nucleotides) of $\alpha \mathrm{ML}$ indicates the utilization of the HIV LTR poly(A) site, and the longer transcript of L $\alpha$ (104 nucleotides) accounts for readthrough from the LTR into the $\alpha 2$-globin gene diverging with the riboprobe at this position. The fainter bands are slight overdigestion products in $\mathrm{L} \alpha$ and are just above the LpA position.

requirement for RNA sequences upstream of the HIV cap site.

Because it is evident that the HIV poly(A) site is efficient in isolation, we wished to confirm that it is wholly inactive or occluded in $\mathrm{L} \alpha$. We therefore compared the levels of L $\alpha$ mRNA 3 ' ends (utilizing the $\alpha$-globin poly(A) site] with a similar construct, with $L \alpha$ in which the HIV poly(A) site is deleted $(\Delta \mathrm{L} \alpha$; Fig. 3A). Each transfection was controlled by the rabbit $\beta$ mRNA cotransfection signal. As indicated by duplicate experiments in Figure $3 \mathrm{~B}$, $\mathrm{L} \alpha$ and $\Delta \mathrm{L} \alpha$ gave the same levels of mRNA $3^{\prime}$ ends utilizing the $\alpha$-globin poly(A) site. That is, the presence or absence of the HIV poly(A) site had no effect on the level of transcripts reading through to the $\alpha$-globin poly(A) site. Figure 3D directly analyzes HIV poly(A) site utilization in L $\alpha$. Using either an S1 probe (panel I) or riboprobe (panel II) L $\alpha$ gave no signal for utilization of the HIV poly(A) site in L $\alpha$, while $\alpha M L$ gave a strong signal and therefore provided a positive control for the Sl and riboprobes.

From these experiments, we conclude that the HIV poly(A) site is an efficient RNA-processing signal, requiring only sequences between the AfIII and Hinfl sites (i.e., within the $5^{\prime}$ LTR transcript). However, this poly(A) site is completely inactive when it is part of the actively transcribing $5^{\prime}$ LTR in L $\alpha$. These results therefore rule out an involvement of RNA signals $5^{\prime}$ to the HIV cap site in HIV poly(A) site activation. Furthermore, the HIV poly(A) site is an efficient RNA-processing signal, consistent with the need for high levels of expression of the HIV genome.
The HIV poly(A) site is occluded by closely positioned promoters while other poly $(A)$ sites remain active

We wished to investigate the specificity of HIV poly(A) site occlusion. Are other poly $|A|$ sites occluded by closely positioned promoters and can the HIV poly $(A)$ site be occluded by a different promoter? To test these possibilities we made a number of hybrid constructs as indicated in Figure 4A. $\mathrm{L} \alpha$ was modified to include a synthetic poly(A) site (Levitt et al. 1989) between the HIV promoter and poly(A) site, and two internal deletions were made in the HIV LTR. The $\Delta T$ deletion removes the Tar sequence, which is known to signal Tat transactivation of the HIV promoter/Cullen and Greene 1989). This sequence is thought to form a stable hairpin loop structure in the RNA and may interact directly with the Tat protein. The proximity of Tar to the HIV poly $(A)$ site raises the possibility that it also has a role in poly $(A)$ site occlusion. The $\Delta A$ deletion removes the AATAAA sequence of the HIV poly(A) site as described above. The $\alpha$-globin promoter was also modified as indicated in Figure $5 \mathrm{~A}$ so that either the HIV poly $(\mathrm{A})$ site $(\alpha \mathrm{L} \alpha)$ or synthetic poly $(\mathrm{A})$ site $(\alpha \mathrm{S} \alpha)$ was positioned directly adjacent to the $\alpha$ promoter. In $\alpha \mathrm{L} \alpha$ the promoter and poly(A) site are 70 nucleotides apart, whereas in $\alpha \mathrm{S} \alpha$ they are only 20 nucleotides apart.

Figure 4B shows the RNA analysis of these various hybrid constructs following their transfection into HeLa cells. In this experiment, RNA that reads through the promoter-adjacent poly $(\mathrm{A})$ site is detected using an $\mathrm{S} 1$ probe for exon 3 of the $\alpha$ gene. As demonstrated before, 

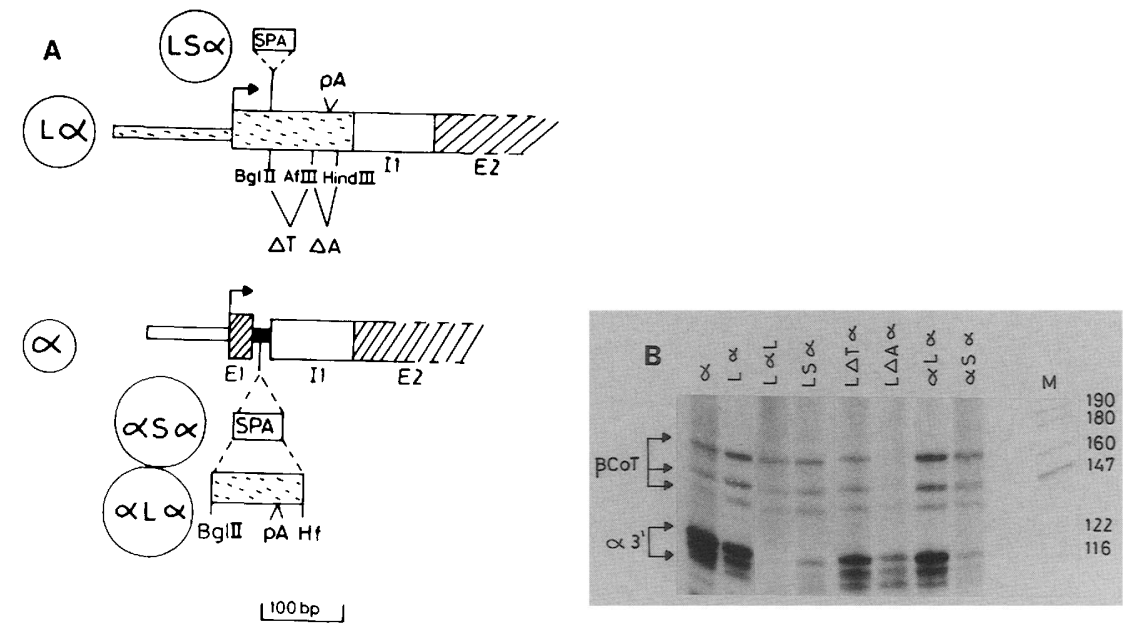

Figure 4. (A) Schematic representation of $L \alpha$ derivative constructs introducing (1) the insertion of a functional synthetic poly $(\mathrm{A})$ site (SPA) (Levitt et al. 1989) into the LTR, adjacent to the HIV LTR promoter region; (2) two deletions within the HIV LTR, by excision through restriction enzyme digestion of, first, the HIV Tar sequence $(\Delta T)$ (Cullen and Greene 1989) and second the poly(A) site itself $(\Delta \mathrm{A})$. Also illustrated are derivative $\alpha 2$-globin constructs in which the SPA as well as the BgIII-HinfI LTR fragment, containing the HIV LTR poly(A) site, have been inserted into the $\alpha$-globin derivative vector, $30 \mathrm{bp}$ adjacent to the $\alpha 2$-globin promoter. Exons (hatched boxes); introns (open boxes); HIV fragments (dashed boxes); flanking sequences (thin boxes); promoters (arrows); poly(A) sites (labeled); polylinker sequences (solid box); and important restriction sites are indicated. (B) S1 nuclease analysis of RNA from HeLa cells transfected with the following plasmid constructs: $\alpha, L \alpha, L \alpha L, L S \alpha, L \Delta T \alpha, L \Delta A \alpha, \alpha L \alpha$, and $\alpha S \alpha$ and cotransfected with R $\beta S V p B R 328$. The S1 DNA probes used in this assay were a BstEII digestion of an $\alpha$ l-globin gene plasmid ( $\alpha 1$ pSVed; Higgs et al. 1983). The $\alpha 2$ mRNA signal is at 110 nucleotides (plus some overdigestion S1 products), the position at which the $\alpha 1$ gene probe and $\alpha 2$ mRNA 3 ' ends diverge in sequence (Michelson and Orkin 1980). The same EcoRI $\beta$ 3' S1 probe was used giving signals as indicated, the $\beta$ larger band being the authentic $\beta$ mRNA 3' end with the two bands below being overdigestion products (due to AT-rich sequence). The amount of $\alpha 2$-globin readthrough signal $\left(\alpha 3^{\prime}\right)$ indirectly determines the level of utilization of the various inserted or deleted poly $(A)$ sites in L $\alpha$ or $\alpha$, taking into account the $\beta$ cotransfection control signal.

L $\alpha$ has significant levels of $\alpha 3^{\prime}$ signal because the poly(A) site is occluded. Similarly, $L \Delta A \alpha$ gives full levels of $\alpha$ readthrough although the transfection in this case was less efficient as judged by the fainter $\beta$ cotransfection signal. Interestingly, L $\Delta \mathrm{T} \alpha$ also gave full levels of $\alpha$ 3 ' signal indicating that the Tar sequence is not involved in poly(A) site occlusion. LaL gave no $\alpha 3^{\prime}$ signal. This is expected since the $3^{\prime}$ end of the $\alpha$ gene is replaced by a second copy of the HIV LTR sequence in L $\alpha$ L. However, LS $\alpha$ also gave only low levels of $\alpha 3^{\prime}$ signal, indicating that the SPA is active when positioned next to the HIV promoter.

Both $\alpha \mathrm{L} \alpha$ and $\alpha \mathrm{S} \alpha$ gave complementary results to the $\mathrm{L} \alpha$ and $\mathrm{LS} \alpha$ gene constructs in that $\alpha \mathrm{L}$ had full levels of $\alpha 3^{\prime}$ signal and $\alpha \mathrm{S}$ had greatly reduced levels.

From these results we can make the following conclusions. First, the HIV poly(A) site is occluded when adjacent to either the HIV or $\alpha$-globin promoters and does not require the HIV Tar sequence for this effect. Second, the SPA is active when adjacent to either the HIV or $\alpha$ promoters as judged by significant reduction in the $\alpha 3^{\prime}$ signal in LS $\alpha$ and $\alpha \mathrm{S}$. This latter conclusion /that the SPA is functional when positioned adjacent to the HIV or $\alpha$-globin promoter) is based on lack of readthrough transcription and is therefore indirect.

We have attempted to identify the tiny transcripts, which we predict must exist, that initiate on the $\alpha$ or HIV promoters and end at the closely following poly $(\mathrm{A})$ site (SPA). We have detected these $\sim 50$ nucleotide transcripts at very low levels (data not shown) and presume that their small size, proximity of cap, and poly $(\mathrm{A})$ tail, as well as lack of introns, makes them highly unstable.
We therefore made additional constructs to test whether the lack of readthrough transcription observed when a non-HIV poly(A) site is positioned close to a promoter is due to the presence of a functional poly(A) signal (see Fig. 5A). First, we have placed the SPA in LS $\alpha$ both in the forward (LS $+\alpha$ ) and reverse (LS $-\alpha$ ) orientations. In the reverse orientation the SPA still possesses an $\mathrm{A}_{2} \mathrm{TA}_{3}$ sequence but lacks GT-rich downstream signals required for poly(A) site activity (Gil and Proudfoot 1987; Levitt et al. 1989). We have also cloned an $\alpha 2$-globin poly(A) site fragment in the same place as SPA in LS $\alpha$ but have used both the wild-type $\alpha$-globin poly $(A)$ site $(L \alpha W \alpha)$ as well as a point mutation $\left(\mathrm{A}_{2} \mathrm{TA}_{3} \rightarrow \mathrm{A}_{2} \mathrm{TA}_{2} \mathrm{G}\right)$ derived from $\alpha$-thalassemia, which is a completely inactive poly(A) site $(\mathrm{L} \alpha \mathrm{M} \alpha)$ (Higgs et al. 1983). Figure 5B shows the RNA analysis of these constructs. First, it is clear that the SPA in LS $\alpha$ is orientation specific as judged by a fivefold reduction in readthrough $\alpha$ transcripts for LS $+\alpha$ but full levels for LS $-\alpha$. With the L $\alpha \alpha$ constructs, both $\mathrm{L} \alpha \mathrm{M}+\alpha$ and $\mathrm{L} \alpha \mathrm{M}-\alpha$ [with the $\alpha$-thalassemia poly(A) site fragment in reverse orientation] gave full levels of $\alpha$ readthrough transcripts. In contrast, $L \alpha W \alpha$ drastically reduced the level of readthrough transcript. These results demonstrate that both a functional $\mathrm{A}_{2} \mathrm{TA}_{3}$ sequence, as well as downstream GT-rich sequences, are required to prevent readthrough transcription. That is, the same elements that are required for a functional poly $(\mathrm{A})$ site are also required to block readthrough transcripts. We conclude that both the SPA and $\alpha$-globin poly(A) sites are functional when adjacent to the HIV promoter while the HIV poly(A) site is fully occluded. 

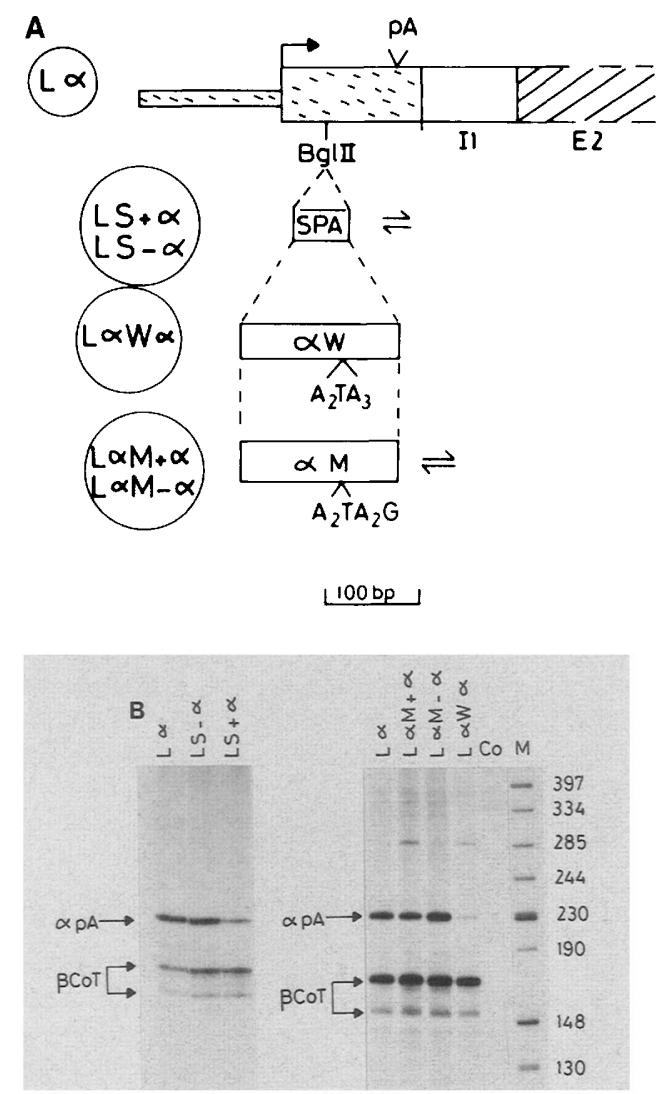

Figure 5. (A) Nomenclature and schematic illustrations of L $\alpha$-derivative constructions, into which were inserted the SPA in both orientations (described previously in one orientation as $\alpha \mathrm{S} \alpha$ in Fig. 5A); the wild-type $\alpha 2$-globin poly $(\mathrm{A})$ site; and the nonfunctional point-mutated $\alpha 2$-globin poly $(A)$ site in both orientations. All poly $(\mathrm{A})$ site inserts are positioned closely adjacent to the HIV LTR promoter. $(B) \mathrm{Sl}$ analysis of RNA from HeLa cells transfected with $\mathrm{L} \alpha, \mathrm{LS}-\alpha, \mathrm{LS}+\alpha, \mathrm{L} \alpha \mathrm{M}+\alpha$, and $\mathrm{L} \alpha \mathrm{W} \alpha$. The cells were cotransfected with RBSVpBR328. The S1 DNA probe used in this assay was obtained from a BstEII digestion of $\alpha$ and labeled with Klenow enzyme. The utilization of the inserted poly $(A)$ sites is indirectly measured through $\alpha$-globin readthrough level. It is important to take into account the quality of transfections based on the $\beta$ cotransfection control.

The GT-rich downstream sequence of the HIV poly(A) site confers $\operatorname{poly}(A)$ site occlusion

We wished to determine which part of the HIV poly $(\mathrm{A})$ site causes it to occlude when close to an active promoter. It has been demonstrated previously that only two specific sequences are required to form an efficient poly(A) site: AATAAA and a downstream GT-rich region (Levitt et al. 1989). The AATAAA sequence is known to be a general feature of mammalian poly $(\mathrm{A})$ sites although in several cases, variants such as ATTAAA and AGTAAA do exist (Wickens and Stephenson 1984). In contrast, the downstream GT-rich sequences are relatively variable between poly(A) sites, although more extensive GT-rich regions are often associated with more efficient poly(A) sites. On the basis of these considerations we reasoned that the AATAAA of the HIV poly(A) site could not itself confer poly(A) site occlusion, whereas the GTrich region was a likely candidate. We therefore made synthetic oligonucleotides containing a 5 '-linker sequence followed by the HIV GT-rich region as shown in Figure 6A. This duplex oligonucleotide was inserted into the plasmid LS $+\alpha$ immediately following the AATAAA of the SPA in place of its downstream GT-rich sequence (called LSH $\alpha$ ). A second construct was then made in which the hybrid SH poly(A) site was excised from LSH $\alpha$ and inserted downstream of the intact $\alpha$-globin genes so that the $\alpha$ and $\mathrm{SH}$ poly(A) sites are positioned in tandem (called $\alpha \mathrm{SH}$ ). The details of how LSH $\alpha$ and LSH were constructed are described in Materials and methods.

Figure 6B shows RNA analysis of $\mathrm{LSH} \alpha$ and $\alpha \mathrm{SH}$, compared with $L \alpha$ and $L S+\alpha$, transfected into HeLa cells. Using an end-labeled DNA probe for the $3^{\prime}$ end of the $\alpha$-globin gene (as in Fig. 3A), full levels of $\alpha$-globin poly(A) site utilization are evident in the $L \alpha$ lane, indicating occlusion of the HIV poly(A) site, while at least a fivefold reduction in the $\alpha$-globin poly(A) site signal (as judged by the $\beta$ cotransfection control signal) is observed in LS $+\alpha$, indicating that the SPA is active adjacent to the HIV promoter as shown previously (Fig. 5B). Analysis of $\mathrm{LSH} \alpha$ reveals full levels of $\alpha$-globin poly(A) site utilization (as in $L \alpha$ ), indicating that the $S H$ poly $(A)$ site is inactive when next to the HIV promoter unlike the SPA (in LS $+\alpha$ ). However, the SH poly|A) site is functional when placed at the $3^{\prime}$ end of $\alpha$ as in $\alpha \mathrm{SH}$. As shown in Figure $6 \mathrm{~B}$, the $\mathrm{SH}$ poly $(\mathrm{A})$ site band is at least twice as
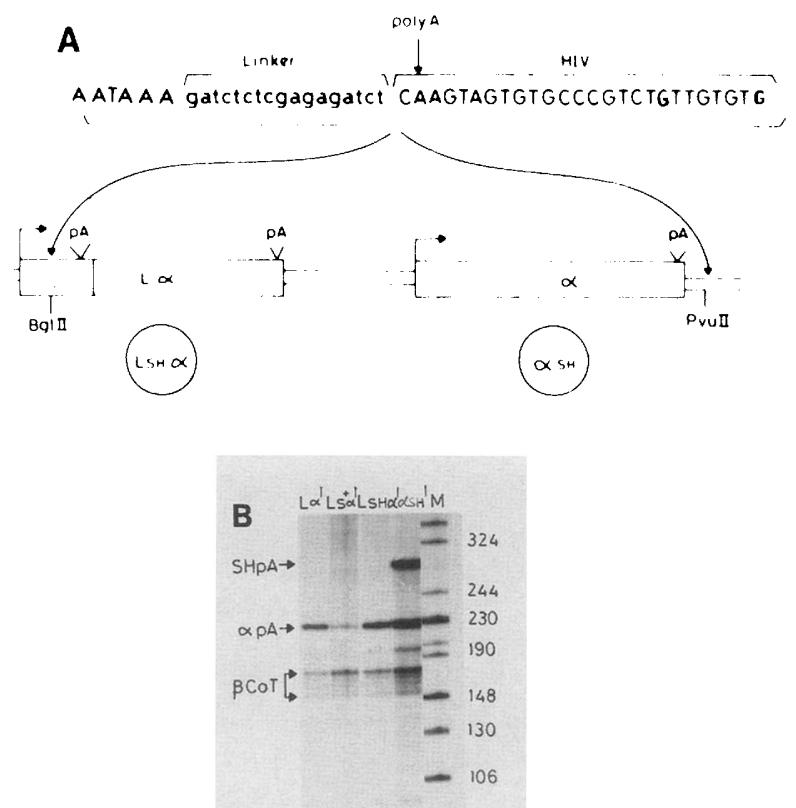

Figure 6. (A) Diagram of LSH $\alpha$ and $\alpha \mathrm{SH}$. Duplexed oligonucleotide containing the linker and HIV downstream region (as shown) are ligated against the AATAAA of the synthetic poly(A) site positioned at the BgIII site in LS $+\alpha$, called LSH $\alpha$. This reconstructed poly $|\mathrm{A}|$ site is then inserted $3^{\prime}$ of the intact $\alpha$-globin gene, called $\alpha \mathrm{SH}$. $(B)$ S1 nuclease analysis of LSH $\alpha$ - and $\alpha$ SH-transfected HeLa cell RNA compared with $\mathrm{L} \alpha$ and $\mathrm{LS}+\alpha$ using DNA probes as described in Fig. 3A. 
strong as $\alpha$. These results demonstrate that the downstream GT-rich region of the HIV poly(A) site confers poly(A) site occlusion properties on a poly(A) site.

Only large-scale spacing between the HIV promoter and $\operatorname{poly}(A)$ site prevents poly $(A)$ site occlusion

We have demonstrated that the HIV poly(A) site is inactive when very close to an active promoter (as in $\mathrm{L} \alpha$ or $\alpha \mathrm{L} \alpha$ ) but highly active when positioned $>1 \mathrm{~kb}$ away from a promoter (as in $L \alpha L, \alpha L$, and $\beta L$ ). This behavior of the HIV poly(A) site is in contrast to the $\alpha$ and synthetic poly(A) sites, which are both active adjacent to promoters. We wished to define more precisely how large a space is required between the promoter and HIV poly $(\mathrm{A})$ site to overcome the occlusion effect. We, therefore, constructed variants of $\mathrm{L} \alpha$ in which increasingly large spacer fragments (derived from phage $\lambda$ DNA) were inserted into the BglII site between the HIV promoter and the poly(A) site (Fig. 7A). Figure 7B shows the S1 analysis of L $\alpha$ RNA probing for $\alpha$-globin poly(A) site utilization. As indicated with a spacer of 75 or 240 nucleotides, full levels of readthrough transcription as compared with $L \alpha$ were observed. Interestingly, with spacers of 310 or 420 nucleotides, a significant drop in the level of $\alpha \mathrm{pA}$ signal was demonstrated, suggesting that the HIV poly(A) site was now active. However, when the $5^{\prime}$ end of the $L \alpha$ constructs was analyzed no detectable HIV poly(A) site band was observed (data not shown), suggesting that these larger spacer constructs were producing unstable mRNAs rather than activating the HIV poly $(\mathrm{A})$ site. To confirm this view, a deleted $L \alpha$ construct was tested in which the HIV poly(A) was removed (L $\Delta \mathrm{A} \alpha$; Fig. 4A). The spacers of 240,310 , and 420 nucleotides were added to $L \Delta A \alpha$, and $\alpha$-globin poly(A) site utilization was measured as before. Figure $7 B$ shows that the spacers of 310 and 420 nucleotides in $\mathrm{L} \Delta \mathrm{A} \alpha$ still gave significantly reduced levels of $\alpha \mathrm{pA}$ signal, confirming that these larger inserts either inhibited the HIV promoter or had reduced mRNA stability, rather than activating the HIV poly|A) site. Indeed, the ratio of $\alpha \mathrm{pA}$ signal between $\mathrm{L} \Delta \mathrm{A} \alpha$ and its two spacer clones 310 and 420 is close to the $\alpha \mathrm{pA}$ ratio for $L \alpha$ and its two spacer clones 310 and 420 . This suggests that these larger inserts still have no effect on increasing the usage of the HIV poly(A) site. We conclude that the HIV poly(A) site is still occluded by an upstream promoter 500 bp away, but at some point beyond this distance it becomes fully active.

\section{Discussion}

The results presented in these studies argue that the HIV poly(A) site possesses specific sequence features that cause it to be occluded when close to a functional promoter. Thus, we demonstrate that the HIV poly(A) site is fully occluded when adjacent to either its homologous HIV promoter or the $\alpha 2$-globin gene promoter. In contrast, two other poly(A) sites are functional when adjacent to these two promoters.

These observations are in contrast to two recently de-
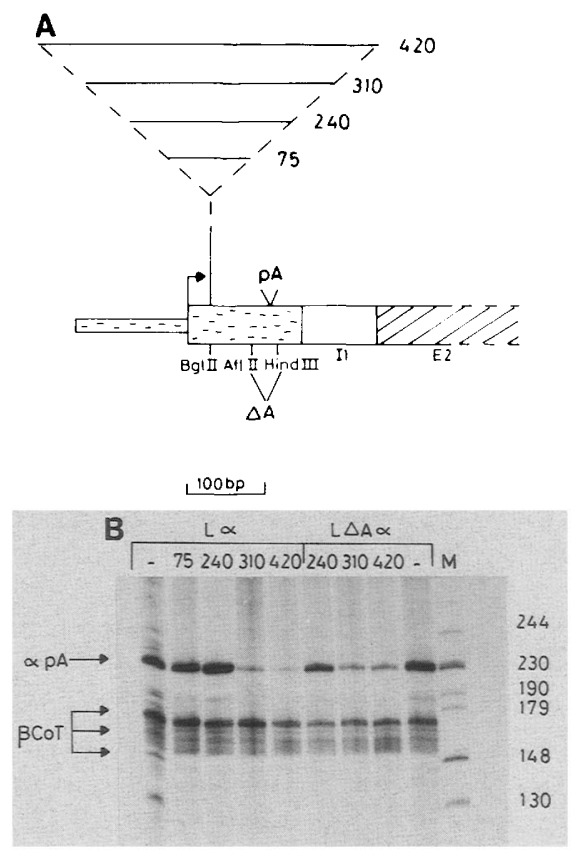

Figure 7. $(A \mid$ Schematic illustration of spacer constructions deriving from $L \alpha$. Exons (hatched boxes); introns (open boxes); HIV fragments (dashed boxes); flanking sequences (thin boxes); promoter (arrow); poly(A) site (pA); and important restriction sites are shown. Additionally represented in this illustration are a further series of spacer constructs deriving from $L \Delta A \alpha$, which corresponds to a modification of $L \alpha$ in the form of a deletion of the HIV LTR poly $(\mathrm{A})$ site (see Materials and methods). Therefore, two series of spacer clones are shown: $L \alpha$ and $L \Delta A \alpha .(B) S 1$ nuclease analysis of RNA from HeLa cells transfected with the $L \alpha$ and $L \Delta A \alpha$ spacer constructs and cotransfected with RßSVpBR328. The BstEII site in the $\alpha 2$-globin gene in $\alpha$ was used to end-label the SI DNA probe. In this assay we probed for the amount of readthrough of each transcript, represented by a digestion product of $230 \mathrm{bp}$. It is important to take into account in the comparative analysis the levels of cotransfection $\beta$ control signals. Note the decrease of $\alpha$ readthrough in the larger spacer constructs in both series.

scribed pararetroviral poly(A) sites, one in the ground squirrel hepatitis B virus (Russnak and Ganem 1990) and the other in the plant cauliflower mosaic virus (CaMV; Sanfaçon and Hohn 1990). Pararetroviruses are transcribed as circular minichromosomes and possess a single LTR sequence. Transcription initiates on the LTR promoter proceeding through the adjacent poly(A) site and around the whole viral genome, and finally utilizes the LTR poly(A) site the second time around. Pararetroviruses are therefore functionally analogous to retroviruses and require a mechanism to occlude the LTR poly(A) site. In the case of the hepatitis B virus, sequences upstream of the cap site are required for the poly(A) site to function. Furthermore, LTR sequences from other retroviruses including HIV can apparently function instead of the hepatitis upstream sequences to activate the hepatitis poly(A) site (Russnak and Ganem 1990). In contrast, the CaMV appears to only partially occlude its promoter-adjacent poly(A) site and does so by 
a simple spacing effect. This poly(A) site works at $66 \%$ efficiency on transcripts initiating on the adjacent promoter (190 bp upstream) but works with $100 \%$ efficiency when artificially separated from the promoter by $\sim 300$ nucleotides (Sanfaçon and Hohn 1990). A second plant poly(A) site was tested in this system (for the nopaline synthetase gene, Nos) and was similarly more active when moved away from the CaMV promoter. This suggests that the sensitivity of poly(A) sites to nearby promoters may be a more general feature of plants rather than specific to pararetroviruses.

The occlusion mechanism for the HIV poly(A) site is surprisingly different from both of the above pararetroviruses. Upstream sequences to the cap site are not required for it to work efficiently. Indeed, a minimal HIV poly(A) site fragment of 60 nucleotides functions in two different locations (both in the 3 '-flanking region of the human $\alpha 2$-globin gene and in the third exon of the rabbit $\beta$-globin gene). The possibility that both locations inadvertently possess upstream sequence elements that activate the HIV poly(A) site seems improbable. Similarly, a simple spacing effect does not account for HIV poly(A) site occlusion. The fact that $\operatorname{poly}(\mathrm{A})$ site occlusion appears to be specific to the HIV poly(A) site and not to two other mammalian poly(A) sites immediately distinguishes the HIV poly(A) site from the situation in CaMV. Also, because the HIV poly(A) site is completely occluded adjacent to a promoter and is only active when positioned $>500$ bp away, a much more efficient poly(A) site occlusion mechanism is indicated. We are therefore forced to conclude that in each of these three cases of poly(A) site occlusion, different mechanisms must operate. Possibly, the very different origins of these three viruses have led to the convergent evolution of these different approaches to poly(A) site occlusion.

These studies demonstrate that the HIV poly $(A)$ site occlusion sequences must be directly associated with the poly(A) signal itself. First, we show that the sequences between the AflII and HinfI sites which border the $\mathrm{A}_{2} \mathrm{TA}_{3}$ and GT-rich elements are required for occlusion. Second, we demonstrate that 26 nucleotides of the HIV poly(A) site downstream region including two GTrich regions confer poly $(\mathrm{A})$ site occlusion properties on a synthetic poly(A) site. We are currently attempting to define these downstream sequences more precisely, as well as to test whether or not other retroviral poly(A) sites possess similar occlusion sequences. Such information may allow us to address the molecular mechanism of this intriguing phenomenon.

\section{Materials and methods}

\section{Plasmid Constructions}

$\alpha, L \alpha, \Delta L \alpha, L \alpha L$ The human $\alpha 2$-globin gene, containing plasmid called $\alpha$ throughout these studies, was originally called $\alpha 2$ W3'PS pSVed, as described by Whitelaw and Proudfoot (1986), and contains the $\alpha$ gene in three exons with $1.1 \mathrm{~kb}$ of $5^{\prime}$-flanking sequence and $2.4 \mathrm{~kb}$ of $3^{\prime}$-flanking sequence. The pSVed vector is based on pBR322 but contains the SV40 origin/ enhancer region to allow expression of the $\alpha$-globin gene in mammalian cells (Proudfoot et al. 1984; Whitelaw et al. 1989). Digestion of $\alpha$ with SmaI excises $\sim 860$ bp of $\alpha 5^{\prime}$-flanking region through to the middle of intron 1 of the $\alpha$-globin gene and thereby deletes the entire $\alpha$-globin promoter. In place of the $\alpha$-globin promoter region, a 300-bp Aval-Hinfl fragment containing the HIV-1 promoter and leader sequence (Fig. 1B) was inserted to generate $\mathrm{L} \alpha . \Delta \mathrm{L} \alpha$ contains a shorter HIV fragment |AvaI-BgIII $\mid$ and therefore lacks most of the HIV leader sequence including the poly $(A)$ signals. $L \alpha L$ was constructed by excising a 700-bp BstEII fragment, including the third exon of the $\alpha$-globin gene and the immediate 3'-flanking region from $L \alpha$, and replacing this with the HIV-1 AvaI-HinfI promoter leader sequence. In this case, the HIV-1 insert derives from pSP65 HA as an EcoRI-SalI fragment and therefore contains polylinker sequence on either side of the HIV insert.

pSP65-HIV LTR HIV-1 LTR fragments AvaI-HinfI and BglII-Hinfl were inserted into the SmaI site of pSP65 (Melton et al. 1984) to generate pSP65 HIV HA and HB.

$\alpha W L, \alpha M L, \alpha W L^{*}, \beta L \quad \alpha$ and a poly(A) site point mutation of $\alpha$ (called $\alpha 2 M 3$ 'PSpSVed; Whitelaw and Proudfoot 1986) were linearized with PvuII, which cuts 100 bp $3^{\prime}$ to the poly(A) site, and either the HIV-1 poly(A) site fragment of $110 \mathrm{bp}$, BglIIHinfl, was inserted to yield $\alpha \mathrm{WL}$ or $\alpha \mathrm{ML}$, or a shorter 60 -bp AflII-HinfI poly $(\mathrm{A})$ site fragment was inserted to yield $\alpha \mathrm{WL}^{*}$. The same AflIl-HinfI HIV poly(A) site was inserted into the $B g I I I$ site in the middle of the third exon of the rabbit $\beta$-globin gene in the plasmid R $\beta S V$ pBR328 (Grosveld et al. 1982; Levitt et al. 1989), to generate $\beta \mathrm{L}$.

$L \lambda \alpha, L \Delta A \alpha, L \Delta T \alpha, L S \pm \alpha, L \alpha W \alpha, L \alpha M \pm \alpha$ Sau3A fragments from phage $\lambda$ of $75,240,310$, and 420 bp were inserted into the $B g$ III site between the HIV promoter and poly $(\mathrm{A})$ site in $\mathrm{L} \alpha$ and $\mathrm{L} \Delta \mathrm{A} \alpha$ to generate $\mathrm{L} \lambda \alpha$ or $\mathrm{L} \lambda \Delta \alpha$. $\mathrm{L} \Delta \mathrm{T} \alpha$ and $\mathrm{L} \Delta \mathrm{A} \alpha$ were constructed by deleting HIV LTR sequences between $B g I I I$ and $A f l I I$ $(\Delta \mathrm{T})$ and $A$ flII and HindIII $(\Delta \mathrm{A})$ in L $\alpha$. A synthetic poly(A) site (SPA) of 54 bp (Levitt et al. 1989) was inserted in to the HIV Bglll site in both orientations in $\mathrm{L} \alpha$ to generate LS $+\alpha$ and LS $-\alpha$. Finally, an Eco0109 fragment of $130 \mathrm{bp}$, containing either the poly(A) site of the $\alpha 2$-globin gene or the same mutated poly(A) site (both orientations), was inserted into the same BglII site in $\mathrm{L} \alpha$ to generate $\mathrm{L} \alpha \mathrm{W} \alpha, \mathrm{L} \alpha \mathrm{M}+\alpha$, and $\mathrm{L} \alpha \mathrm{M}-\alpha$.

$\alpha L \alpha, \alpha S \alpha$ A functional promoter fragment from the Smal site at -90 to the HinfI site at +20 in the human $\alpha$-globin gene (also containing some polylinker sequence including the BamHI site in pUC9 immediately following the $\alpha$-globin +20 HinfI site) was inserted into SmaI-cut $\alpha$. This yielded an $\alpha$-globin gene construct lacking most of exon 1 and half of intron 1 but containing a polylinker site into which either the SPA or HIV LTR $B g I I-H i n f I$ fragments were inserted to generate $\alpha \mathrm{S} \alpha$ and $\alpha \mathrm{L} \alpha$, respectively.

$L S H \alpha, \alpha S H$ Duplexed synthetic oligonucleotides (for detailed sequence, see Fig. 6A) were blunt-end-ligated into LS $+\alpha$ cut at a BglII site immediately 3 ' to the SPA AATAAA sequence and a HindIII site in exon 2 of the $\alpha$-globin gene to form LSH $\alpha$. $\alpha \mathrm{SH}$ was made by purifying an $\mathrm{SH}$ poly(A) site fragment excised from LSH $\alpha$ by cutting at the PvuII site (just $5^{\prime}$ to the HIV cap site) and a HinclI site immediately $3^{\prime}$ to the HindIII site in exon 2 of $\alpha$-globin. This fragment was inserted into the $3^{\prime}$-flanking region of $\alpha$ at the PvuII site.

In all the plasmid constructions described above, the presence and orientation of inserts were determined by restriction enzyme analysis. The isolation of vector and insert DNA fragments was obtained by either agarose or polyacrylamide gel electrophoresis purification, depending on the size of the DNA fragment in question. If vector or insert DNA fragments were rendered blunt-ended, this was achieved by filling in ends with Klenow DNA polymerase enzyme and dNTP. Ligations were 
performed at room temperature, and transformations were carried out in the NM554 strain of Escherichia coli.

\section{Cell transfection and RNA analysis}

The methods used for growth and transient transfection of HeLa cells, isolation of cytoplasmic RNA, and S1 nuclease analysis have been described previously (Johnson et al. 1986; Levitt et al. 1989). All HeLa cell transfections with the various HIV/ $\alpha$-plasmids were cotransfected with a second plasmid R $3 S V$ pBR328. This plasmid has the dual function of providing SV40 T antigen to allow replication of all the HIV/ $\alpha$-plasmids (which contain SV40 origins of replication) as well as rabbit $\beta$-globin mRNA, which is used as internal control in most of the RNA mapping experiments described in these studies.

RNase protection analysis of cytoplasmic RNA was carried out as described by Melton et al. (1984), with the following modifications of conditions: Hybridizations were performed at $51^{\circ} \mathrm{C}$ and RNase $\mathrm{A}$ and $\mathrm{T}_{1}$ digestions were done at $16^{\circ} \mathrm{C}$. All S1 nuclease or RNase digestion products were electrophoresed through $4-8 \%$ polyacrylamide $/ 7 \mathrm{M}$ urea sequencing gels with a variation in the percent of polyacrylamide, depending on the size range of the products expected. Size markers were generated by digestion of sequenced plasmids with various restriction enzymes.

\section{Acknowledgments}

C.W. is funded by an AIDS MRC studentship and by a grant from The Joseph Goerres Gesellschaft. These studies were funded by a Wellcome project grant (16354) to N.J.P. We gratefully acknowledge William James and Tim Humphrey for advice and encouragement throughout these studies.

The publication costs of this article were defrayed in part by payment of page charges. This article must therefore be hereby marked "advertisement" in accordance with 18 USC section 1734 solely to indicate this fact.

\section{References}

Bateman, E. and M. Paule. 1988. Promoter occlusion during rRNA transcription. Cell 54: 985-992.

Bohnlein, S., J. Hauber, and B.R. Cullen. 1989. Identification of a U5-specific sequence required for efficient polyadenylation within the human immunodeficiency virus long terminal repeat. I. Virol. 63: 421-424.

Cullen, B.R. and W.C. Greene. 1989. Regulatory pathways goveming HIVI replication. Cell 58: 423-426.

Cullen, B.R., P.T. Lomedico, and G. Ju. 1984. Transcriptional interference in avian retroviruses-Implications for promoter insertion model of leukaemogenesis. Nature 307: 241-245.

Gil, A. and N.J. Proudfoot. 1987. Position-dependent sequence elements downstream of AAUAAA are required for efficient rabbit $\beta$ globin mRNA $3^{\prime}$ end formation. Cell 49: 399-406.

Grosveld, G.C., E. deBoer, C.K. Shewmaker, and R.A. Flavell. 1982. DNA sequences necessary for transcription of the rabbit $\beta$ globin gene in vivo. Nature 295: 120-126.

Henderson, S.L., K. Ryan, and B. Sollner-Webb. 1989. The promoter-proximal rRNA termination augments initiation by preventing disruption of the stable transcription complex caused by polymerase read-in. Genes $\Theta$ Dev. 3: 212-223.

Higgs, D.R., S.E.Y. Goodbourn, J. Lamb, J.B. Clegg, D.J. Weatherall, and N.J. Proudfoot. 1983. $\alpha$-Thalassaemia caused by a polyadenylation signal mutation. Nature 306: 398-400.
Humphrey, T. and N.J. Proudfoot. 1988. A beginning to the biochemistry of polyadenylation. Trends Genet. 4: 243-245.

Johnson, M., C. Norman, M.A. Reeve, J. Scully, and N.J. Proudfoot. 1986. Tripartite sequences within and $3^{\prime}$ to the sea urchin H2A histone gene display properties associated with a transcriptional termination process. Mol. Cell. Biol. 6: 4008-4018.

Jones, J.A. 1989. HIV trans-activation and transcriptional control mechanisms. The New Biologist 1: 127-135.

Ju, G. and B.R. Cullen. 1985. The role of avian retroviral LTRs in the regulation of gene expression and viral replication. Adv. Virus Res. 30: 179-223.

Levitt, N., D. Briggs, A. Gil, and N.J. Proudfoot. 1989. Definition of an efficient poly(A) site. Genes \& Dev. 3: 1019-1025.

Melton, D.A., P.A. Krieg, M.R. Rebagliati, T. Maniatis, K. Zinn, and M.R. Green. 1984. Efficient in vitro synthesis of biologically active RNA and RNA hybridization probes from plasmids containing a bacteriophage SP6 promoter. Nucleic ACids Res. 12: 7035-7056.

Michelson, A.M. and S.H. Orkin. 1980. The $3^{\prime}$ untranslated regions of the duplicated human $\alpha$-like globin genes are unexpectedly divergent. Cell 22: 371-377.

Proudfoot, N.J., T.R. Rutherford, and G.A. Partington. 1984. Transcriptional analysis of human zeta globin genes. EMBO I. 3: 1533-1540.

Ratner, L.A., L.L. Fisher, M. Jagodzinski, H. Mitsuya, R.-S. Liou, R.C. Gallo, and F. Wong-Staal. 1987. Complete nucleotide sequences of functional clones of the AIDS virus. AIDS Res. 3: 57-69.

Russnak, R. and D. Ganem. 1990. Sequences $5^{\prime}$ to the polyadenylation signal mediate differential poly(A) site use in hepatitis B viruses. Genes \&) Dev. 4: 764-776.

Sanfaçon, H. and T. Hohn. 1990. Proximity to the promoter inhibits recognition of cauliflower mosaic virus polyadenylation signal. Nature 346: 81-84.

Varmus, H. 1988. Retroviruses. Science 240: 1427-1435.

Whitelaw, E. and N.J. Proudfoot. 1986. $\alpha$-Thalassaemia caused by a poly(A) site mutation reveals that transcriptional termination is linked to $3^{\prime}$ end processing in the human $\zeta$ globin gene. EMBO /. 5: 2915-2922.

Whitelaw E., P. Hogben, O. Hanscombe, and N.J. Proudfoot. 1989. Transcriptional promiscuity of the human $\alpha$-globin gene. Mol. Cell. Biol. 9: 241-251.

Wickens, M. and P. Stephenson. 1984. Role of the conserved AAUAAA sequence: Four AAUAAA point mutations prevent messenger RNA $3^{\prime}$ end formation. Science 226: 10451051 . 


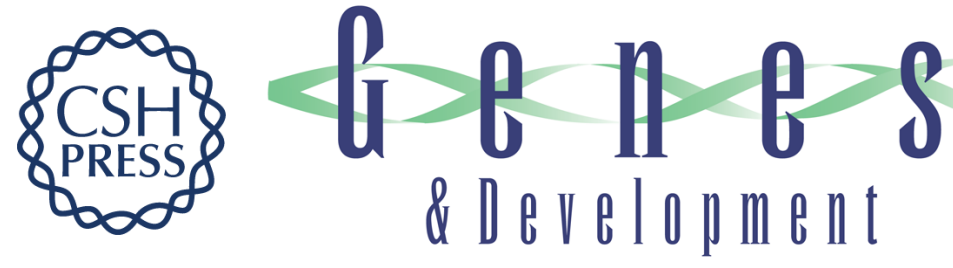

\section{Occlusion of the HIV poly(A) site.}

C Weichs an der Glon, J Monks and N J Proudfoot

Genes Dev. 1991, 5:

Access the most recent version at doi:10.1101/gad.5.2.244

References This article cites 23 articles, 8 of which can be accessed free at: http://genesdev.cshlp.org/content/5/2/244.full.html\#ref-list-1

\section{License}

Email Alerting Receive free email alerts when new articles cite this article - sign up in the box at the top Service right corner of the article or click here.

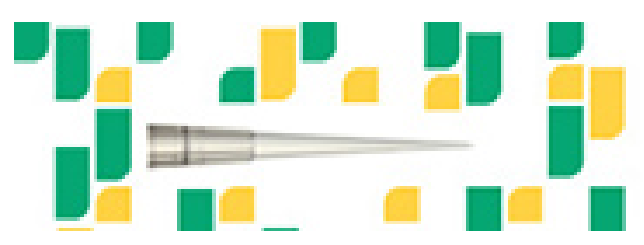

Focused on your science. 